\title{
Group B streptococci vaginal colonization and drug susceptibility pattern among pregnant women attending in selected public antenatal care centers in Addis Ababa, Ethiopia
}

Solomon Assefa ${ }^{1 *}$, Kassu Desta ${ }^{2}$ and Tsehaynesh Lema ${ }^{3,4}$

\begin{abstract}
Background: Group B Streptococcus (GBS) is the leading cause of septicemia, meningitis, and pneumonia in neonates. Maternal colonization with GBS is the principal risk factor for early-onset disease in infants. Group B Streptococcus is now an important cause of maternal and neonatal morbidity and mortality in many parts of the world. In Ethiopia, few studies have been done on GBS colonization among pregnant women. The aim of this study was to determine the prevalence of GBS colonization, antimicrobial susceptibility patterns and assess risk factors among pregnant women.

Methods: A prospective cross-sectional study was conducted from May to August 2014 at selected public antenatal care (ANC) centers in Addis Ababa, Ethiopia. Clinical and socio-demographical data were collected using structured questionnaire after obtaining written informed consent. A total of 281 lower vaginal swabs were collected and inoculated into $1 \mathrm{ml}$ Todd Hewitt Broth supplemented with gentamicin and nalidixic acid to prevent the growth of contaminants. After overnight incubation, all broths were subcultured on 5\% sheep blood agar for isolation of GBS. Antimicrobial susceptibility testing was performed according to the criteria of the Clinical and Laboratory Standard Institute (CLSI) guidelines 2013 by disk diffusion method. Data were entered and analysed using SPSS version 20.0 software. Chi-square test and binary logistic regression analysis were used. $P$-value $<0.05$ was considered statistically significant.

Results: The overall prevalence of GBS colonization among pregnant women was 14.6\% (41/281). Group B Streptococcus colonization was significantly associated with health institutions $(P<0.05)$. All GBS isolates were susceptible to chloramphenicol. Resistance to tetracycline, cefotaxime, clindamycin, penicillin, vancomycin, ampicillin and erythromycin was 90.2\%, 34.1, 26.8\%, 19.5, 17\%, 14.6 and 7.5\% respectively. Multidrug resistance (MDR) $(\geq 2$ drugs) was detected in $43.9 \%$ (18/41) of the isolates.

Conclusion: There was a high frequency of GBS colonization (14.6\%) and resistance to the commonly used antibiotics which suggests the importance of the screening of GBS colonization in pregnant women at 3537 weeks of gestation and testing their antimicrobial susceptibilities in order to provide antibiotic prophylaxis and minimize newborn infection and co-morbidity.
\end{abstract}

Keywords: Antimicrobial susceptibility testing, Group B streptococci, Prevalence, Risk factors

\footnotetext{
*Correspondence: sole.lab2000@yahoo.com; solomonas64@gmail.com

${ }^{1}$ Ethiopian Public Health Institute, P.O. Box 1242, Arbegnoch Street, Addis

Ababa, Ethiopia

Full list of author information is available at the end of the article
}

(C) The Author(s). 2018 Open Access This article is distributed under the terms of the Creative Commons Attribution 4.0 International License (http://creativecommons.org/licenses/by/4.0/), which permits unrestricted use, distribution, and reproduction in any medium, provided you give appropriate credit to the original author(s) and the source, provide a link to the Creative Commons license, and indicate if changes were made. The Creative Commons Public Domain Dedication waiver (http://creativecommons.org/publicdomain/zero/1.0/) applies to the data made available in this article, unless otherwise stated. 


\section{Background}

Group B Streptococcus emerged as the leading cause of neonatal morbidity and mortality in the United States in the 1970s [1-3], with a frequency of 2-3 cases per 1000 live vertical transmission births [4] and case-fatality ratios as high as 50\% [3]. Group B Streptococcus is one of the most important causes of neonatal sepsis, meningitis, and pneumonia [5-7]. Group B Streptococcus neonatal infection could be early-onset GBS disease (EOGBSD), which occurs within the first week of life, and late-onset GBS disease (LOGBSD), which occurs between one week to 3 months of age $[4,5]$.

During pregnancy, approximately $10-30 \%$ of women are colonized with GBS in vagina $[8,9]$ and $60 \%$ of their infants acquire this organism through birth canal [6]. Maternal colonization with GBS in the genitourinary or gastrointestinal tract and transmission to the infant during the labor and delivery process is the principal risk factor for early-onset invasive GBS disease [2, 3, 9].

The widespread use of intrapartum antibiotic prophylaxis to prevent early-onset GBS disease has raised concern about the development of antibiotic resistance among GBS isolates [3]. In the absence of a licensed GBS vaccine [3], universal screening of mothers for vaginal or rectal GBS colonization at 35 to 37 weeks of gestation and selective intrapartum antibiotic prophylaxis (IAP) for all screen-positive women is the strategy currently recommended to reduce incidence of colonization in neonates and prevent early-onset GBS-related diseases $[3,9,10]$.

Group B Streptococcus is now recognized to be an important cause of maternal and neonatal morbidity and mortality in many parts of the world $[6,7]$; however, it has been little studied in Ethiopia [11, 12]. Therefore, this study was conducted to determine the prevalence of GBS colonization, antimicrobial susceptibility pattern and assess risk factors related to GBS among pregnant women attending in selected public ANC centers at Addis Ababa, Ethiopia.

\section{Methods}

\section{Study design and setting}

A prospective cross-sectional study was conducted among pregnant women attending ANC clinics of ALERT Center, Alem Bank, and Woreda 03 health centers, Addis Ababa, Ethiopia from May to August 2014. ALERT Center is one of the specialized tertiary referral hospitals in the country. While the two health centers are mainly engaged in routine antenatal care and delivery service in addition to other health routine care deliveries.

\section{Study population, sample size, and sampling technique} A total of 281 pregnant women (from 35 to 37 weeks of gestation) attending the routine ANC follow up were screened for GBS colonization at ALERT Center $(n=$ 141), Alem Bank $(n=88)$ and Woreda $03(n=52)$ Health centers. Eligible study participants were enrolled in this study using consecutive sampling technique. The sample size was calculated based on the prevalence indicated in the previous study using single population proportion formula [12]. Expected margin of error (d) was 0.05 and confidence interval (z) was $95 \%$. Contingency for the unknown circumstance was $10 \%$. Pregnant women with a premature rupture of membranes (PROM) and history of antibiotic(s) use within two weeks prior to recruitment were excluded from this study.

\section{Data collection}

After obtaining written informed consent, socio-demographic and clinical data were collected using a structured questionnaire. Moreover, recent HIV result was taken from study participants' medical records. Data were collected by well-trained gynaecologist and midwives.

\section{Specimen collection and transport}

Vaginal swabs were taken from the lower vagina using sterile cotton swab according to the Center for Disease Control and Prevention (CDC) and American College of Obstetricians and Gynecologists (ACOG) guidelines [3, 13], and inoculated directly into Todd-Hewitt broth (THB) (Oxoid Ltd., Basingstoke, Hampshire, England) and immediately transported to the Microbiology Laboratory of ALERT Center for further analysis.

\section{Culture and identification of group B streptococci}

The vaginal swabs were placed into $1 \mathrm{ml}$ THB (Oxoid Ltd., Basingstoke, Hampshire, England) supplemented with gentamicin $(8 \mu \mathrm{g} / \mathrm{ml})$ (Intas pharmaceutical Ltd., Matoda village, Ahmedabad, Gujarat, India) and nalidixic acid $(15 \mu \mathrm{g} / \mathrm{ml})$ (Sigma Aldrich, Italy) to prevent growth of contaminants [3]. The broth was incubated for $18-24 \mathrm{~h}$ at $35-37{ }^{\circ} \mathrm{C}$ and inoculated on $5 \%$ sheep blood agar (SBA) (Oxoid Ltd., Basingstoke, Hampshire, England) and incubated overnight in $5 \% \mathrm{CO}_{2}$ atmosphere for 18-24 h. Broth cultures showing no visible turbidity after overnight incubation were re-incubated for additional hours and then subcultured after $48 \mathrm{~h}$ on SBA. Suspected GBS colonies (pink colonies, with narrow beta-hemolysis) were confirmed by Gram stain, catalase test and Christie, Atkins, and Munch-Peterson (CAMP) test.

\section{Antimicrobial susceptibility testing}

Antimicrobial Susceptibility Testing was performed according to Clinical and Laboratory Standard Institute guidelines (CLSI) guidelines 2013 using Kirby-Bauer disk diffusion method [14]. Direct colony suspension in sterile saline, equivalent to 0.5 McFarland standard was 
done and inoculated on Muller-Hinton agar (MHA) (Oxoid Ltd., Basingstoke, Hampshire, England) with 5\% sheep's blood using a sterile cotton swab. An antibiotic disk (Oxoid Ltd., Basingstoke, Hampshire, England) was placed on the agar with clindamycin and erythromycin disks placed $16 \mathrm{~mm}$ from each other in order to detect inducible resistance to clindamycin (D-zone test) and incubated at $35-37{ }^{\circ} \mathrm{C}$ with $5 \% \mathrm{CO}_{2}$ atmosphere for 18 $24 \mathrm{~h}$. The zone of growth inhibition was measured using the Oxoid ruler (Oxoid Ltd., Basingstoke, Hampshire, England) and Linex ruler (Linex 116, Denmark). The antibiotics used were penicillin $(\mathrm{P})(10 \mu \mathrm{g})$, ampicillin (AMP) $(10 \mu \mathrm{g})$, erythromycin $(\mathrm{E})(15 \mu \mathrm{g})$, clindamycin (DA) $(2 \mu \mathrm{g})$, vancomycin $(30 \mu \mathrm{g})$, cefotaxime (CTX) $(30 \mu \mathrm{g})$, chloramphenicol(C) $(30 \mu \mathrm{g})$ and tetracycline (TE) $(30 \mu \mathrm{g})$. The result was interpreted according to CLSI guidelines 2013 as susceptible, intermediate or resistant [14].

\section{Quality control}

The sterility of culture media was checked by incubating overnight at $35-37^{\circ} \mathrm{C}$ without specimen inoculation. Enterococcus faecalis (ATCC 29212), S. agalactiae (ATCC 27956), S. pyogenes (ATCC 19615), S. aureus (ATCC 25923) and E. coli (ATCC 25922) strains were used as a quality control organisms for culture and antimicrobial susceptibility testing.

\section{Data analysis}

Data were coded, entered, cleaned and analyzed by using SPSS version 20.0 software. Frequency distribution, percentage, tables, and charts were used to present results. Explanatory variables were individually cross-tabulated with the outcome variable and statistical significance assessed using chi-square and logistic regression model. A $p$-value less than 0.05 was considered statistically significant.

\section{Ethical consideration}

This study was approved and ethically cleared by the Departmental Ethics and Research Committee (DERC) of Department of Medical Laboratory Science, College of Health Science, Addis Ababa University (AAU) (Ref.No.: MLS/501/14and protocol No.: DRERC 056/13/MLS), Armauer Hansen Research Institute / All African Leprosy, Tuberculosis, Rehabilitation and Training Center (AHRI/ALERT) Ethical Review Committee (AAERC) (Project Reg. No.:PO17/14), Institutional Review Board (IRB) of Addis Ababa Health Bureau (Ref.No.: AAHB/ 5900/227) and National Research Ethics Review Committee (NRERC) (Ref.No.: 3.10/796/06). Official permission from the study sites was obtained. Written informed consent was obtained from each study participant. All participants' results were kept confidentially.

\section{Results}

Socio-demographic characteristics

A total of two hundred eighty-one (281) pregnant women (from 35 to 37 weeks of gestation) were enrolled from May to August 2014. The age of the study participants ranged from 18 to 39 years with a mean age of 26 . $46( \pm 4.41)$ years. Most of the study the participants were between the ages of 25-29 years 120 (42.7\%). Most of the study participants were married (97.5\%). The majority of the study participants were housewives (68.3\%) (Table 1).

\section{Group B Streptococcus colonization}

The overall prevalence of GBS colonization among pregnant women at 35-37 weeks of gestation was 14.6\% (41/ $281)$. The prevalence of GBS in the three health institutions was 20 (22.7\%), 17 (12.1\%) and 4 (7.7\%) in Alem Bank health center, ALERT center, and Woreda 03 health center respectively.

\section{Antimicrobial susceptibility testing}

The antimicrobial susceptibility testing results of GBS isolates are summarized in Table 2. All GBS isolates were $100 \%$ susceptible to chloramphenicol. Most isolates ( $80.5 \%$ to $92.5 \%)$ were susceptible to penicillin G, vancomycin, ampicillin, and erythromycin. Most GBS isolates $(90.2 \%)$ were resistant to tetracycline (Table 2).

Table 1 Socio-demographic characteristics of pregnant women investigated for GBS at three health institutions $(n=281)$

\begin{tabular}{lll}
\hline Socio-demographic characteristics & Frequency & Percentage \\
\hline Health Institutions & 141 & $50.2 \%$ \\
ALERT Center & 52 & $18.5 \%$ \\
Woreda 03 Health Center & 88 & $31.3 \%$ \\
Alem Bank Health Center & & \\
Age groups & 8 & $2.8 \%$ \\
15-19 & 85 & $30.2 \%$ \\
$20-24$ & 120 & $42.7 \%$ \\
$25-29$ & 49 & $17.4 \%$ \\
$30-34$ & 19 & $6.8 \%$ \\
$\geq 35$ & & \\
Marital status & 274 & $97.5 \%$ \\
Married & 4 & $1.4 \%$ \\
Single & 2 & $0.7 \%$ \\
Divorced & 1 & $0.4 \%$ \\
Widowed & & \\
Occupation & 35 & $12.5 \%$ \\
Civil Servant & 192 & $68.3 \%$ \\
House Wives & 54 & $19.2 \%$ \\
Business Women & & \\
\hline
\end{tabular}


Table 2 Antimicrobial susceptibility pattern of GBS isolates from pregnant women recruited from three health institutions $(n=41)$

\begin{tabular}{lllll}
\hline Antibiotics & Disk Potency $(\mu \mathrm{g})$ & Susceptible & Intermediate & Resistant \\
\hline Chloramphenicol $(C)$ & 30 & $41(100 \%)$ & 0 & 0 \\
Erythromycin (E) & 15 & $38(92.5 \%)$ & 0 & $3(7.5 \%)$ \\
Ampicillin (AMP) & 10 & $35(85.4 \%)$ & 0 & $6(14.6 \%)$ \\
Vancomycin (VA) & 30 & $34(83 \%)$ & 0 & $7(17 \%)$ \\
Penicillin G (P) & 10 & $33(80.5 \%)$ & 0 & $8(19.5 \%)$ \\
Clindamycin (DA) & 2 & $30(73.2 \%)$ & 0 & $11(26.8 \%)$ \\
Cefotaxime (CTX) & 30 & $27(65.9 \%)$ & 0 & $14(34.1 \%)$ \\
Tetracycline (TE) & 30 & $3(7.3 \%)$ & $1(2.4 \%)$ & $37(90.2 \%)$ \\
\hline
\end{tabular}

\section{Multi-drug resistance pattern}

Multidrug resistance (MDR) ( $\geq 2$ drugs) was detected in $43.9 \%(18 / 41)$ of the isolates. Resistance to $2,3,4,5$ and 6 drugs was found to be $38.88 \%, 5.55,27.77 \%, 11.11$ and $16.66 \%$ respectively (Table 3 ).

\section{Risk factors for group B streptococci Socio-demographic factors}

The association of socio-demographic variables with GBS colonization is summarized in Table 4. In univariate analysis, GBS colonization showed statistically significant association with health institutions $(P<0.05)$. However, there was no statistically significant association between GBS colonization and age group, marital status and occupation $(P>0.05)$. This study revealed a higher GBS colonization rate among pregnant women of age group $15-19$ years $(25 \%)$ than the age group $\geq 35$ years $(10.5 \%)$. However, the difference was not statistically significant $(\mathrm{P}>0.05)$. In multivariable logistic regression analysis,

Table 3 Multi-drug resistance pattern of GBS isolated from pregnant women recruited from three health institutions $(n=41)$

\begin{tabular}{lll}
$\begin{array}{l}\text { Drugs resistance pattern } \\
\text { (Antibiogram) }\end{array}$ & $\begin{array}{l}\text { No. of drug to which } \\
\text { strains were resistant }\end{array}$ & $\begin{array}{l}\text { No. of resistant } \\
\text { strains (\%) }\end{array}$ \\
\hline CTX:TE & 2 & $2(11.11)$ \\
DA:TE & 2 & $1(5.55)$ \\
E: TE & 2 & $1(5.55)$ \\
TE: VA & 2 & $3(16.66)$ \\
CTX: DA: TE & 3 & $1(5.55)$ \\
AMP: CTX: E: TE & 4 & $1(5.55)$ \\
CTX: DA: P: TE & 4 & $2(11.11)$ \\
CTX:DA:P:VA & 4 & $1(5.55)$ \\
CTX:DA:TE:VA & 4 & $1(5.55)$ \\
AMP: CTX: DA: P:TE & 5 & $2(11.11)$ \\
AMP: CTX: DA: E: P: TE & 6 & $1(5.55)$ \\
AMP:CTX: DA: P: TE: VA: & 6 & $2(11.11)$ \\
\hline
\end{tabular}

TE Tetracycline, CTX Cefotaxime, VA Vancomycin, DA: Clindamycin, $E$ Erythromycin, $P$ Penicillin G, AMP Ampicillin
GBS colonization was significantly associated with health institutions $(\mathrm{P}<0.05)$ (Table 4$)$.

\section{Obstetric factors}

In univariate analysis, GBS colonization did not show statistically significant association with the number of antenatal visits, gravidity, history of spontaneous abortion and stillbirth $(P>0.5)$. Pregnant women with no history of stillbirth (14.9\%) showed higher GBS colonization rates than those mothers with a history of stillbirth (7.7\%). However, the difference was not statistically significant $(P>0.05)$ (Table 5).

\section{HIV infection}

Of 281 pregnant women screened for GBS colonization, $25(8.9 \%)$ were HIV positive. Among the pregnant women with HIV infection, 6 (24\%) were positive for GBS and among pregnant women with HIV negative, 35 (13.7\%) were GBS positive. However, this difference was not statistically significant $(\mathrm{P}>0.05)$ (Table 5$)$. The Confounding effect of HIV infection was checked as its biological plausibility is expected with GBS colonization, but statistically failed to be found independently significantly associated.

\section{Discussion}

In this study, the overall prevalence of GBS among pregnant women was $14.6 \%$. This finding was almost similar with reports from other developing countries; in Malawi (16.5\%) and Nigeria (11.3\%) [15, 16], but higher than those reported in Gondar, North Ethiopia (9\%) and Mozambique (1.8\%) [11, 17] and slightly lower than those reported in Hawassa, South Ethiopia (20.8\%), Tanzania (23\%) and Zimbabwe (21\%) [6, 12, 18]. The finding of this study was also comparable to the studies done in some European countries; in North-Eastern Italy (17.9\%) by Busetti M et al., Turin, Italy (18\%) by Savoia $\mathrm{D}$ et al., and Poland (17.2\%) [19-21], but higher than those reported in Northern Greece (6.6\%) [22], and slightly lower than those reported in Switzerland (21\%), UK (21.3\%) and Netherlands (21\%) [23-25]. 
Table 4 Association between socio-demographic factors and GBS colonization among pregnant women at three health institutions $(n=281)$

\begin{tabular}{|c|c|c|c|c|c|c|c|}
\hline \multirow{2}{*}{$\begin{array}{l}\text { Socio demographic } \\
\text { factors }\end{array}$} & \multirow[t]{2}{*}{ Total } & \multicolumn{2}{|l|}{ GBS Culture } & \multirow[t]{2}{*}{ COR (95\% C.I) } & \multirow[t]{2}{*}{$p$-value ${ }^{a}$} & \multirow[t]{2}{*}{ AOR(95\% C.I) } & \multirow[t]{2}{*}{$p$-value } \\
\hline & & $\begin{array}{l}\text { GBS negative } \\
N(\%)\end{array}$ & $\begin{array}{l}\text { GBS positive } \\
N(\%)\end{array}$ & & & & \\
\hline \multicolumn{8}{|l|}{ Age group } \\
\hline $15-19$ & 8 & $6(75)$ & $2(25)$ & $2.83(0.32-24.8)$ & 0.35 & & \\
\hline $20-24$ & 85 & $72(84.7)$ & 13(15.3) & $1.54(0.32-7.45)$ & 0.59 & & \\
\hline $25-29$ & 120 & $102(85)$ & $18(15)$ & $1.50(0.32-7.06)$ & 0.61 & & \\
\hline $30-34$ & 49 & $43(87.8)$ & $6(12.2)$ & $1.19(0.22-6.47)$ & 0.84 & & \\
\hline$\geq 35$ & 19 & 17(89.5) & $2(10.5)$ & 1 & & & \\
\hline \multicolumn{8}{|l|}{ Health Institutions } \\
\hline ALERT Center & 141 & 124(87.9) & $17(12.1)$ & 1 & & 1 & \\
\hline Woreda $03 \mathrm{HC}$ & 52 & 48(92.3) & $4(7.7)$ & $0.61(0.20-1.90)$ & 0.392 & $0.71(0.22-2.27)$ & 0.568 \\
\hline Alem Bank HC & 88 & $68(77.3)$ & $20(22.7)$ & $2.15(1.05-4.37)$ & $0.035^{*}$ & $2.63(1.22-5.65)$ & $0.013^{*}$ \\
\hline \multicolumn{8}{|l|}{ Marital Status } \\
\hline Married & 274 & 234(85.4) & $40(14.6)$ & 1 & & & \\
\hline Single & 4 & $3(75)$ & $1(25)$ & $1.95(0.20-19.2)$ & 0.57 & & \\
\hline Divorced & 2 & $2(100)$ & $0(0.0)$ & 0.000 & 0.99 & & \\
\hline Widowed & 1 & $1(100)$ & $0(0.0)$ & 0.000 & 1.00 & & \\
\hline \multicolumn{8}{|l|}{ Occupation } \\
\hline Civil servant & 35 & $32(91.4)$ & 3(8.6) & 1 & & & \\
\hline House wife & 192 & 163(84.9) & 29(15.1) & $1.9(0.55-6.61)$ & 0.314 & & \\
\hline Business women & 54 & $45(83.3)$ & $9(16.7)$ & $2.13(0.54-8.51)$ & 0.283 & & \\
\hline
\end{tabular}

*Significant at $p$-value $<0.05 ;{ }^{1}$ indicates logical reference group or constant; $C l$ Confidence Interval, COR Crude odds ratio, $A O R$ Adjusted odds ratio, ${ }^{a} p$-value obtained by binary; ${ }^{\mathrm{b}} p$-value obtained by multiple logistic regression; HC: Health Center; ${ }^{\mathrm{N}}$ Number; ${ }^{\%}$ Percentage

The result of our study was also almost similar with the studies conducted in Texas, USA (12.2\%) [26], and in Brazil ranging from $14.6 \%$ to 20.4 [27-29], but higher than those reported in Argentina (7.6\%) [30].The finding of this study (14.6\%) was higher than reports from some Asian countries; such as Taiwan (6.2\%), India (2.3\%), China (7.1\%) and Korea (8.3\%) [31-34]. The variations between countries could possibly be due to differences in the sample size and type of sites cultured, culture methods, socio-economic status, sexual behavior and geographic areas.

In this study, GBS colonization was significantly associated with health institutions $(P<0.05)$. This finding was consistent with reports from another study [34]. Those pregnant women who were managed in Alem Bank Health center were 2.6 times more likely to be colonized with GBS compared to those pregnant women who were managed in the ALERT center (AOR: 2.6, 95\% C.I: $1.22-5.65)$. This difference might be due to specimen collection techniques of health care providers. Those providers in the centers with lower GBS rates may not have used proper hygienic sampling techniques including insertion of the swab into the vaginal. Therefore, it needs further investigation to confirm the relationship between GBS colonization and health institutions.

Group B Streptococcus colonization in this study was higher in HIV infected pregnant women, though the association was not significant. GBS colonization and HIV infection $(P>0.05)$. This might probably be due to the small number of HIV infected pregnant women among the studied population. Similar findings have been reported in studies conducted in Tanzania and Malawi [6, 35]. However, a study conducted in the Democratic Republic of Congo, colonization rate was significantly associated with HIV infection [36].

In the present study, we observed that primigravida women were more often associated with GBS colonization, though it was not statistically significant $(P>0.05)$. Similar findings have been reported in Ethiopia (2012), Nigeria and Brazil [12, 15, 28]. However, in another study colonization rates were found to be significantly greater among multigravida women than primigravida women $(P<0.001)[32,34,37]$. This might be due to geographical variation. Therefore, further studies are needed to confirm the correlation between gravidity and colonization by GBS from the different geographical location. 
Table 5 Association between obstetric factors and GBS colonization among pregnant women at three health institutions ( $n=281$ )

\begin{tabular}{|c|c|c|c|c|c|c|c|}
\hline \multirow{2}{*}{$\begin{array}{l}\text { Obstetric } \\
\text { Factors }\end{array}$} & \multirow[t]{2}{*}{ Total } & \multicolumn{2}{|l|}{ GBS culture } & \multirow[t]{2}{*}{ COR (95\% C.I) } & \multirow[t]{2}{*}{$p$-value ${ }^{a}$} & \multirow[t]{2}{*}{ AOR (95\% C.I) } & \multirow[t]{2}{*}{$p$-value ${ }^{b}$} \\
\hline & & $\begin{array}{l}\text { GBS negative } \\
N(\%)\end{array}$ & $\begin{array}{l}\text { GBS positive } \\
N(\%)\end{array}$ & & & & \\
\hline \multicolumn{8}{|l|}{ ANC visit } \\
\hline One times & 6 & $5(83.3)$ & $1(16.7)$ & $1.12(0.13-10.1)$ & 0.917 & & \\
\hline Two times & 37 & $32(86.5)$ & $5(13.5)$ & $0.88(0.31-2.51)$ & 0.808 & & \\
\hline Three times & 99 & $85(85.9)$ & $14(14.1)$ & $0.93(0.45-1.92)$ & 0.836 & & \\
\hline Four times & 139 & 118(85.4) & 21(14.6) & 1 & & & \\
\hline \multicolumn{8}{|l|}{ Type of Gravida } \\
\hline Primigravida & 88 & $74(84.1)$ & 14(15.9) & $1.16(0.58-2.35)$ & 0.673 & & \\
\hline Multigravida & 193 & $166(86)$ & $27(14)$ & 1 & & & \\
\hline \multicolumn{8}{|l|}{ Still birth } \\
\hline No & 268 & 228(85.1) & $40(14.9)$ & 1 & & & \\
\hline Yes & 13 & $12(92.3)$ & $1(7.7)$ & $0.48(0.06-3.76)$ & 0.480 & & \\
\hline \multicolumn{8}{|l|}{ Abortion } \\
\hline No & 211 & 180(85.3) & $31(14.7)$ & 1 & & & \\
\hline Yes & 70 & $60(85.7)$ & $10(14.3)$ & $0.97(0.45-2.09)$ & 0.934 & & \\
\hline \multicolumn{8}{|l|}{ HIV Infection } \\
\hline No & 256 & $221(86.3)$ & 35 (13.7) & 1 & & 1 & \\
\hline Yes & 25 & $19(76)$ & $6(24)$ & $1.99(0.75-5.34)$ & 0.170 & $2.8(0.97-8.11)$ & 0.057 \\
\hline
\end{tabular}

${ }^{1}$ Iogical reference; $\mathrm{Cl}$ Confidence interval, COR Crude odds ratio, AOR Adjusted odds ratio, ${ }^{\mathrm{N}}$ Number; ${ }^{\%}$ Percentage; ${ }^{\mathrm{a}} p$-value obtained by binary; ${ }^{\mathrm{b}} p$-value obtained by multiple logistic regression; Adjusted for HIV status

In the present study, history of spontaneous abortion did not influence GBS colonization in pregnant women. Similar findings have been reported in studies conducted in Tanzania and India [6, 32]. However, in another studies history of spontaneous abortion showed significant association with GBS colonization [34, 36]. Therefore, further studies are needed to confirm the correlation between abortion and colonization by GBS. The previous history of stillbirth did not influence GBS colonization. The lack of association with this factor might be explained by the fact that the numbers of participants in this study with such risk factor were small. This finding was consistent with studies from Dar es Salaam, Tanzania (2009) by Joachim A et al. [6].

Penicillin and ampicillin are the drugs of choice for prevention or treatment of GBS infections, and clindamycin and erythromycin are the recommended alternatives for patients who are allergic to ß-lactam agents. The widespread use of these antibiotics to prevent earlyonset GBS disease has raised concern about the development of antibiotic resistance among GBS isolates [3].

In this study, all GBS isolates were susceptible to chloramphenicol. In our study, we observed resistance to penicillin (19.5\%) and ampicillin (14.6\%) which are the first choice of drugs for intrapartum prophylaxis. This did not match with the CDC 2010 guidelines study, which did not find any resistance to penicillin. These findings were comparable to those reported in another study [15]. The expanded use of beta-lactam antimicrobials in the treatment of several infective clinical syndromes and the free accessibility of purchase over the counter might be the cause of the emergence of GBS resistance strains in this environment.

The CDC 2010 guideline recommends testing of GBS isolates for susceptibility to clindamycin and erythromycin, as they are the drugs of choice for penicillin-allergic women at high risk for anaphylaxis [3]. An increase in resistance of GBS to erythromycin has been reported [1, 15, 38-41]. In this study, we found that $7.5 \%$ of the isolates were resistant to erythromycin. This was consistent with reports from other studies [6, 7, 12, 42, 43]. This rate of erythromycin resistance in the GBS isolates strongly supports the current $\mathrm{CDC}$ recommendation that antibiotic susceptibility test should be performed if erythromycin therapy is needed to prevent neonatal GBS infection. With respect to resistance to clindamycin, the finding of this study (26.8\%) was similar to those reports from other studies $[6,15,38-41,43,44]$. Since clindamycin is another alternative antibiotic recommended by the CDC for pregnant women who are allergic to penicillin, the resistance level underline the need of carrying out a susceptibility test. This might be due to the widespread use of the antibiotics. 
Vancomycin is recommended for GBS-colonized mothers with a high risk of anaphylaxis to penicillin and if the isolate is resistant to clindamycin [3]. In this study, we found that $17 \%$ of the isolates were resistant to vancomycin. This finding was comparable to those reported in another study [15]. Since vancomycin is another alternative drug recommended by the $\mathrm{CDC}$ for pregnant women who are allergic to penicillin and clindamycin-resistant isolates, the resistance level underline the need of carrying out a susceptibility test. Most GBS isolates (90.2\%) were resistant to tetracycline which showed consistency with reports from other studies [12, $32,38,42,45]$. This may probably be due to the widespread use of this antibiotics and ease of procurement of antibiotic and/or could be attributed to the indiscriminate use of antimicrobial drugs in this area. The cefotaxime resistance $(34.1 \%)$ in this study was difficult to explain since cefotaxime was rarely used in Ethiopia. In contrast to this, high susceptibility to cefotaxime was observed in other studies $[15,42]$.

\section{Conclusion}

There was high isolation rate of GBS (14.6\%) among pregnant women. The resistance of the isolates to the commonly used antibiotics including penicillin, ampicillin, and clindamycin in this study calls for screening of all pregnant women at 35-37 weeks of gestation. Performing susceptibility testing before administration of any of these antibiotics to provide antibiotic prophylaxis to GBS carrier is necessary. The finding of this study also signifies that GBS infection might be a silent clinical problem that is undiagnosed in the present study area, therefore, it requires advocacy work for awareness and concerted effort for preventive measures.

\section{Abbreviations \\ ACOG: American college of obstetricians and gynecologists; AHRI: Armauer hansen research institute; ALERT: All african leprosy, tuberculosis, \\ rehabilitation and training center; ANC: Antenatal care; ATCC: American type culture collection; CAMP Test: Christie, atkins, munch, peterson test; CDC: Center for disease control and prevention; CLSI: Clinical and laboratory standard institute; DRERC: Departmental research and ethics review committee; EOGBSD: Early-onset group B streptococcal disease; GBS: Group B streptococci; HIV: Human immunodeficiency virus; IAP: Intrapartum antibiotics prophylaxis; IRB: Institutional review board; LOGBSD: Late- onset group B streptococcal disease; MHA: Muller Hinton Agar; NRERC: National research ethics review committee; PROM: Premature rupture of membranes; SBA: Sheep blood agar; SPSS: Statistical package for social sciences; THB: Todd hewitt broth}

\section{Acknowledgements}

We would like to acknowledge the School of Allied Health Sciences, College of Health Sciences, Department of Medical Laboratory Sciences, Addis Ababa University, for the remarkable efficiency of their service and dedication to duty. Next, we would like to express our sincere gratitude to all ethical approval committee. Our gratitude also extends to the study sites for their official permission and support during specimen collection. Special thanks go to all study participants for their participation, without them this study would not have been realized.
Funding

The fund for this research project was covered by the principal investigator.

\section{Availability of data and materials}

The data sets used and/or analyzed during the current study are available from the corresponding author on reasonable request. This is to keep all study participants' result confidentiality.

\section{Authors' contributions}

AS and LT conceived and designed the study. AS wrote the study protocol, supervised the data collection, did the laboratory work, did the analysis and interpretation of data, wrote the first draft and participated in all revisions till the final version of this paper. DK \& LT contributed to the analysis, interpretation of results, revising the manuscript critically for intellectual content. All authors read and approved the final version of the manuscript for publication.

\section{Authors' information}

AS: Assistant researcher II (BSC, MSc), TB focal person in National Laboratory Capacity Building Directorate, Ethiopian Public Health Institute, Addis Ababa, Ethiopia. DK: Lecturer, assistant professor (BSC, MSC, Ph.D. candidate) at the Department of Medical Laboratory Science, School of Allied Health Sciences, College of Health Sciences, Addis Ababa University, Addis Ababa, Ethiopia. LT: Medical Microbiologist (BSC, MSc, Ph.D. candidate) at ALERT Center Clinical Laboratory and Armauer Hansen Research Institute, ALERT Center, Addis Ababa, Ethiopia.

\section{Ethics approval and consent to participate}

This study was approved and ethically cleared by the DERC of Department of Medical Laboratory Science, College of Health Science, Addis Ababa University (Ref.No.: MLS/501/14 and protocol No.: DRERC 056/13/MLS), AHRI/ ALERT Ethical Review Committee (AAERC) (Project Reg. No.: PO17/14), IRB of Addis Ababa Health Bureau (Ref.No.: AAHB/5900/227) and NRERC (Ref. No.: 3.10/796/06). Official permission from the study sites was obtained. Written informed consent was obtained from each study participant.

\section{Competing interests}

The authors declare that they have no competing interests.

\section{Publisher's Note}

Springer Nature remains neutral with regard to jurisdictional claims in published maps and institutional affiliations.

\section{Author details}

${ }^{1}$ Ethiopian Public Health Institute, P.O. Box 1242, Arbegnoch Street, Addis Ababa, Ethiopia. ${ }^{2}$ Department of Medical Laboratory Sciences, School of Allied Health Sciences, College of Health Sciences, Addis Ababa University, P.O. Box 1176, Addis Ababa, Ethiopia. ${ }^{3}$ Armauer Hansen Research Institute, P.O. Box 1005, Jimma Road, Addis Ababa, Ethiopia. ${ }^{4}$ All Africa Leprosy, Tuberculosis, Rehabilitation and Training Center, P.O. Box 165, Jimma Road, Addis Ababa, Ethiopia.

Received: 11 May 2016 Accepted: 26 April 2018

Published online: 04 May 2018

\section{References}

1. Phares CR, Lynfield R, Farley MM, Mohle-Boetani J, Harrison LH, Petit S, et al. Epidemiology of invasive group B streptococcal disease in the United States, 1999-2005. JAMA. 2008;299(17):2056-65. https://doi.org/10.1001/jama. 299.17.2056.

2. Committee on Infectious Diseases and Committee on Fetus and Newborn, Baker CJ, Byington CL, Polin RA. Policy Statement - Recommendations for the prevention of perinatal group B streptococcal (GBS) disease. Pediatrics. 2011;128(3):611-6. https://doi.org/10.1542/peds.2011-1466.

3. Verani JR, McGee L, Schrag SJ. Prevention of perinatal group B streptococcal disease: Revised guidelines from CDC, 2010: Department of Health and Human Services, Centers for Disease Control and Prevention,2010 Nov 19 Contract No: RR-10.

4. Faro S, Brehm B, Smith F, Mouzoon M, Greisinger A, Wehmanen O, et al. Screening for group B streptococcus: a private hospital's experience. Infect Dis Obstet Gynecol. 2010;2010:1-4. https://doi.org/10.1155/2010/451096. 
5. Maisey HC, Doran KS, Nizet V. Recent advances in understanding the molecular basis of group B Streptococcus virulence. Expert Rev Mol Med. 2008;10:e27. https://doi.org/10.1017/S1462399408000811.

6. Joachim A, Matee MI, Massawe FA, Lyamuya EF. Maternal and neonatal colonisation of group B streptococcus at Muhimbili National Hospital in Dar es salaam, Tanzania: prevalence, risk factors and antimicrobial resistance. BMC Public Health. 2009;9:437. https://doi.org/10.1186/1471-2458-9-437.

7. Ezeonu I, Agbo M. Incidence and anti-microbial resistance profile of group B Streptococcus (GBS) infection in pregnant women in Nsukka, Enugu state, Nigeria. Afr J Microbiol Res. 2014;8(1):91-5. https://doi.org/10.5897/AJMR12.2307.

8. El Beitune P, Duarte G, Maffei CM. Colonization by Streptococcus agalactiae during pregnancy: maternal and perinatal prognosis. Braz J Infect Dis. 2005; 9(4):276-82. doi:/S1413-86702005000400002

9. El Aila NA, Tency I, Claeys G, Saerens B, Cools P, Verstraelen H, et al. Comparison of different sampling techniques and of different culture methods for detection of group B streptococcus carriage in pregnant women. BMC Infect Dis. 2010;10:285. https://doi.org/10.1186/1471-2334-10-285.

10. Cheng PJ, Chueh HY, Liu CM, Hsu JJ, Hsieh TT, Soong YK. Risk factors for recurrence of group $B$ streptococcus colonization in a subsequent pregnancy. Obstet Gynecol. 2008;111(3):704-9. https://doi.org/10.1097/AOG. 0b013e318163cd6b.

11. Schmidt J, Halle E, Halle H, Mohammed T, Gunther E. Colonization of pregnant women and their newborn infants with group B streptococci in the Gondar College of Medical Sciences. Ethiop Med J. 1989;27(3):115-9.

12. Mohammed M, Asrat D, Woldeamanuel $Y$, Demissie A. Prevalence of group B Streptococcus colonization among pregnant women attending antenatal clinic of Hawassa health center, Hawassa, Ethiopia. Ethiop J Health Dev. 2012;26(1):36-42

13. American College of $O$, Gynecologists Committee on Obstetric P. ACOG Committee Opinion No. 485: Prevention of early-onset group B streptococcal disease in newborns. Obstet Gynecol Annu. 2011;117(4):101927. https://doi.org/10.1097/AOG.0b013e318219229b.

14. Cockerill FR. Performance standards for antimicrobial susceptibility testing: twenty-third informational supplement. Clinical Laboratory Standards Institute; 2013

15. Onipede A, Adefusi O, Adeyemi A, Adejuyigbe E, Oyelese A, Ogunniyi T. Group B streptococcus carriage during late pregnancy in lle-lfe, Nigeria. Afr J Clin Exp Microbiol. 2012;13(3):135-43.

16. Dzowela T, Komolafe O, Igbigbi A. Prevalence of group B Streptococcus colonization in antenatal women at the queen Elizabeth central hospital, Blantyre-a preliminary study. Malawi Med J. 2006;17(3):97-9.

17. De Steenwinkel FD, Tak HV, Muller AE, Nouwen $J$, Oostvogel PM, Mocumbi SM. Low carriage rate of group B streptococcus in pregnant women in Maputo, Mozambique. Tropical Med Int Health. 2008;13(3):427-9. https://doi. org/10.1111/j.1365-3156.2008.02018.x.

18. Mavenyengwa RT, Afset JE, Schei B, Berg S, Caspersen T, Bergseng H, et al. Group B Streptococcus colonization during pregnancy and maternal-fetal transmission in Zimbabwe. Acta Obstet Gynecol Scand. 2010;89(2):250-5. https://doi.org/10.3109/00016340903398029.

19. Busetti M, D'Agaro P, Campello C. Group B streptococcus prevalence in pregnant women from north-eastern Italy: advantages of a screening strategy based on direct plating plus broth enrichment. J Clin Pathol. 2007; 60(10):1140-3. https://doi.org/10.1136/jcp.2006.043489.

20. Savoia D, Gottimer C, Crocilla C, Zucca M. Streptococcus agalactiae in pregnant women: phenotypic and genotypic characters. J Inf Secur. 2008; 56(2):120-5. https://doi.org/10.1016/j.jinf.2007.11.007.

21. Strus M, Pawlik D, Brzychczy-Wloch M, Gosiewski T, Rytlewski K, Lauterbach $R$, et al. Group B streptococcus colonization of pregnant women and their children observed on obstetric and neonatal wards of the University Hospital in Krakow, Poland. J Med Microbiol. 2009;58(2):228-33. https://doi. org/10.1099/jmm.0.002865-0.

22. Tsolia M, Psoma M, Gavrili S, Petrochilou V, Michalas S, Legakis N, et al. Group B streptococcus colonization of Greek pregnant women and neonates: prevalence, risk factors and serotypes. Clin Microbiol Infect. 2003; 9(8):832-8.

23. Rausch AV, Gross A, Droz S, Bodmer T, Surbek DV. Group B streptococcus colonization in pregnancy: prevalence and prevention strategies of neonatal sepsis. J Perinat Med. 2009;37(2):124-9. https://doi.org/10.1515/JPM.2009.020.
24. Jones N, Oliver K, Jones Y, Haines A, Crook D. Carriage of group B streptococcus in pregnant women from Oxford, UK. J Clin Pathol. 2006; 59(4):363-6. https://doi.org/10.1136/jcp.2005.029058.

25. Valkenburg-van den Berg AW, Sprij AJ, Oostvogel PM, Mutsaers JA, Renes $W B$, Rosendaal FR, et al. Prevalence of colonisation with group $B$ streptococci in pregnant women of a multi-ethnic population in the Netherlands. Eur J Obstet Gynecol Reprod Biol. 2006;124(2):178-83. https:// doi.org/10.1016/j.ejogrb.2005.06.007.

26. Chohan L, Hollier LM, Bishop K, Kilpatrick CC. Patterns of antibiotic resistance among group B streptococcus isolates: 2001-2004. Infect Dis Obstet Gynecol. 2006;2006:57492. https://doi.org/10.1155/IDOG/2006/57492.

27. Zusman AS, Baltimore RS, Fonseca SN. Prevalence of maternal group B streptococcal colonization and related risk factors in a Brazilian population. Braz J Infect Dis. 2006;10(4):242-6.

28. Simoes JA, Alves VM, Fracalanzza SE, de Camargo RP, Mathias L, Milanez $H M$, et al. Phenotypical characteristics of group B streptococcus in parturients. Braz J Infect Dis. 2007:11(2):261-6.

29. Costa AL, Lamy Filho F, Chein MB, Brito LM, Lamy ZC, Andrade KL. Prevalence of colonization by group B Streptococcus in pregnant women from a public maternity of northwest region of Brazil. Rev Bras Ginecol Obstet. 2008;30(6):274-80.

30. Quiroga M, Pegels E, Oviedo P, Pereyra E, Vergara M. Antibiotic susceptibility patterns and prevalence of group B Streptococcus isolated from pregnant women in Misiones, Argentina. Braz J Microbiol. 2008;39(2):245-50. https:// doi.org/10.1590/S1517-83822008000200009.

31. Yang MJ, Sun PL, Wen KC, Chao KC, Chang WH, Chen CY, et al. Prevalence of maternal group B streptococcus colonization and vertical transmission in low-risk women in a single institute. J Chin Med Assoc. 2012;75(1):25-8. https://doi.org/10.1016/j.jcma.2011.10.011.

32. Sharmila V, Joseph NM, Arun Babu T, Chaturvedula L, Sistla S. Genital tract group B streptococcal colonization in pregnant women: a south Indian perspective. J Infect Dev Ctries. 2011:5(8):592-5. https://doi.org/10.3855/jidc.1551.

33. Lu B, Li D, Cui Y, Sui W, Huang L, Lu X. Epidemiology of group $B$ streptococcus isolated from pregnant women in Beijing. China Clin Microbiol Infect. 2014;20(6):370-3. https://doi.org/10.1111/1469-0691.12416.

34. Kim EJ, Oh KY, Kim MY, Seo YS, Shin JH, Song YR, et al. Risk factors for group B streptococcus colonization among pregnant women in Korea. Epidemiol Health. 2011;33:1-7. https://doi.org/10.4178/epih/e2011010.

35. Gray KJ, Kafulafula G, Matemba M, Kamdolozi M, Membe G, French N. Group B Streptococcus and HIV infection in pregnant women, Malawi, 2008-2010. Emerg Infect Dis. 2011;17(10):1932-5. https://doi.org/10.3201/eid1710.102008.

36. Mitima KT, Ntamako S, Birindwa AM, Mukanire N, Kivukuto JM, Tsongo K, et al. Prevalence of colonization by Streptococcus agalactiae among pregnant women in Bukavu, Democratic Republic of the Congo. J Infect Dev Ctries. 2014:8(9):1195-200. https://doi.org/10.3855/jidc.5030.

37. Orrett FA. Colonization with group B streptococci in pregnancy and outcome of infected neonates in Trinidad. Pediatr Int. 2003;45(3):319-23.

38. Wang H, Zhao C, He W, Zhang F, Zhang L, Cao B, et al. High prevalence of fluoroquinolone-resistant group B streptococci among clinical isolates in China and predominance of sequence type 19 with serotype III. Antimicrob Agents Chemother. 2013;57(3):1538-41. https://doi.org/10.1128/AAC.02317-12

39. Capanna F, Emonet SP, Cherkaoui A, Irion O, Schrenzel J, Martinez de Tejada B. Antibiotic resistance patterns among group B Streptococcus isolates: implications for antibiotic prophylaxis for early-onset neonatal sepsis. Swiss Med Wkly. 2013;143:1-4. https://doi.org/10.4414/smw.2013.13778.

40. DiPersio LP, DiPersio JR. High rates of erythromycin and clindamycin resistance among OBGYN isolates of group B Streptococcus. Diagn Microbiol Infect Dis. 2006;54(1):79-82. https://doi.org/10.1016/j.diagmicrobio. 2005.07.003.

41. Yook JH, Kim MY, Kim EJ, Yang JH, Ryu HM, Oh KY, et al. Risk factors associated with group B streptococcus resistant to clindamycin and erythromycin in pregnant korean women. Infect Chemother. 2013;45(3): 299-307. https://doi.org/10.3947/ic.2013.45.3.299.

42. Boswihi SS, Udo EE, Al-Sweih N. Serotypes and antibiotic resistance in group B streptococcus isolated from patients at the maternity hospital, Kuwait. J Med Microbiol. 2012;61(1):126-31. https://doi.org/10.1099/jmm.0.035477-0.

43. Castellano-Filho DS, da Silva VL, Nascimento TC, de Toledo Vieira M, Diniz CG. Detection of group B Streptococcus in Brazilian pregnant women and 
antimicrobial susceptibility patterns. Braz J Microbiol. 2010;41(4):1047-55. https://doi.org/10.1590/S1517-838220100004000024.

44. Frohlicher S, Reichen-Fahrni G, Muller M, Surbek D, Droz S, Spellerberg B, et al. Serotype distribution and antimicrobial susceptibility of group B streptococci in pregnant women: results from a Swiss tertiary centre. Swiss Med Wkly. 2014;144:w13935; https://doi.org/10.4414/smw.2014.13935.

45. Hannoun A, Shehab M, Khairallah MT, Sabra A, Abi-Rached R, Bazi T, et al. Correlation between group B streptococcal genotypes, their antimicrobial resistance profiles, and virulence genes among pregnant women in Lebanon. Int J Microbiol. 2009;2009:1-6. https://doi.org/10.1155/2009/ 796512

Ready to submit your research? Choose BMC and benefit from:

- fast, convenient online submission

- thorough peer review by experienced researchers in your field

- rapid publication on acceptance

- support for research data, including large and complex data types

- gold Open Access which fosters wider collaboration and increased citations

- maximum visibility for your research: over $100 \mathrm{M}$ website views per year 